\title{
Prediction and prevention of the first psychotic episode: new directions and opportunities
}

\author{
This article was published in the following Dove Press journal: \\ Therapeutics and Clinical Risk Management \\ 28 March 2014 \\ Number of times this article has been viewed
}

\section{Sara Piras \\ Gianluca Casu \\ Maria Antonietta Casu \\ Alessandro Orrù \\ Stefania Ruiu \\ Antonio Pilleri \\ Gabriella Manca \\ Giorgio Marchese}

National Research Council, Institute of Translational Pharmacology,

Strategic Operating Unit of Cagliari, Cagliari, Italy
Correspondence: Giorgio Marchese National Research Council, Institute of Translational Pharmacology, UOS of Cagliari, Loc Piscinamanna, BId 5, POLARIS, I-090I0 Pula, Cagliari, Italy Tel +39709242026

Fax +39709242206

Email giorgio.marchese@cnr.it

\begin{abstract}
In the last few decades, substantial research has focused on the possibility of early detection and prevention of the first psychotic episode in young individuals at risk of developing this mental disturbance; however, unresolved clinical and ethical issues still call for further investigations. New perspectives and opportunities may come from the identification of selective psychopathological and instrumental markers linking the appearance of subtle psychotic symptoms with the clinical outcome of specific mental pathologies. Furthermore, empirically derived algorithms and risk staging models should facilitate the identification of targeted prevention therapies, possibly improving the efficacy of well-tolerated therapeutic approaches, such as psychological interventions and natural compound supplementations. To date, the collected evidence on the efficacy and tolerability of pharmacological prevention therapies raises more doubts than hopes. A very early detection of risk and appropriate symptomatic pattern classifications may provide a chance to better match prevention strategies with the development of psychosis.
\end{abstract}

Keywords: psychosis, risk, basic symptoms, schizophrenia, therapy

\section{Introduction}

Subtle motor, emotional, cognitive, and behavioral alterations are often observed in young individuals who later develop schizophrenia, leading several authors to hypothesize that early detection and prevention strategies may provide an opportunity to reduce the incidence of an unfavorable outcome of the disease, and possibly to prevent the development of the first psychotic episode (FEP). ${ }^{1-3}$ This hypothesis was supported by clinical analyses indicating that the duration of untreated psychosis is often associated with an incomplete symptom remission, greater risk of relapse, and poor quality of life. ${ }^{4}$ Several studies have also suggested that therapeutic interventions may ameliorate the outcome of the disease when promptly administered to first-episode schizophrenia patients. ${ }^{4,5}$ Furthermore, it has been reported that schizophrenic individuals often show anatomical and physiological modifications in different brain structures, such as frontal and temporal cortical lobes, hippocampus, thalamus, and basal ganglia. ${ }^{5}$ These brain alterations have been associated with schizophrenia symptoms and functioning decline, providing further support for the concept that the appearance of FEP should be counteracted from a very early stage. ${ }^{5}$

The development of prevention strategies in the field of psychosis, however, raises several clinical and ethical problems. The temporal course of psychotic symptoms often implies that preventive interventions should be applied to young individuals. During late puberty and young adulthood, youths are generally experiencing the turmoil of 
adolescence in which hormonal, emotional, and social factors have a large bearing on destabilizing their behavior. Moreover, brain structures regulating mood, personality, and functioning are known to complete their maturation during adolescence and early adulthood, on the basis of a preordained process in which brain morphological and physiological modifications seem to be particularly susceptible to internal and external stimuli. ${ }^{6}$ In this framework, the possibility of applying a prevention program is strongly connected with the ability to precisely identify only those individuals who later develop FEP. Likewise, the development of prevention therapies with an adequate balance between efficacy and tolerability, which should fulfill the criteria of a minimal disturbance of the normal maturation processes occurring in adolescence and early adulthood, is critical.

Recently, several studies have evaluated the potential applicability of early detection and prevention strategies in the field of psychosis. ${ }^{1-3}$ New psychometric instruments have been developed to better predict the appearance of FEP. Furthermore, some attempts have been carried out in order to modify the course of premorbid subthreshold symptoms before the development of a full-blown psychosis. ${ }^{7}$ Although the results of these studies are promising and some specific features of the prodromal phase of psychosis have already been identified, the fifth edition of the Diagnostic and Statistical Manual of Mental Disorders (DSM-V) ${ }^{8}$ proposed "attenuated psychosis syndrome" (formerly known as "psychosis risk syndrome") within a category of mental conditions needing further investigation.

With this purpose in mind, the present analysis intends to review the research on this topic, taking into account the complex relationships linking the assessment of the risk of developing psychosis with the identification of efficacious prevention strategies.

\section{Prediction strategies}

Several research groups have focused on the possibility of defining a prodromal set of symptoms and signs that may predict the development of FEP. Particularly, two main approaches have independently provided the rationale for the development of reliable predictive psychometric scales, namely the basic symptom (BS) and the ultra-high risk (UHR) approaches. ${ }^{9}$ The BS approach was developed to specifically predict the development of schizophrenia, while the UHR criteria aimed to evaluate the risk of developing FEP, regardless of the psychiatric diagnosis associated with the appearance of psychotic symptoms. In the last few years, these two approaches have been partially conjoined in the attempt to improve the sensitivity (ability to identify positive subjects) and specificity (ability to avoid negative cases) of predictive psychometric scales, with consequent modifications of their selectivity in predicting the development of a specific psychotic disorder. Most of all, both BS and UHR criteria have indispensably contributed to the development of recent predictive strategies, such as empirically based algorithms and risk staging models.

\section{The BS approach}

The BS concept (BSc) has been delineated since the 1950s by Gross and Huber, who identified some characteristic subclinical disturbances affecting schizophrenic individuals in every stage of the illness, including the prodromal phase to FEP, residual states, and possibly frank psychosis. ${ }^{9}$ The peculiarity of the BSc consists in the patients' awareness of their mental disturbance, which is often accompanied by self-concern and associated with coping behaviors. It has also been underlined that BS possibly represent the earliest self-perceived experience of psychosis and the most immediate symptomatic expression of the neurobiological deficits of schizophrenia, thus explaining the use of the term "basic"., 9,10

BS were categorized by taking into account their qualitative characteristics and incidence during the evolution of the disease. Some early "uncharacteristic" BS are often self-experienced by patients several years prior to FEP, and may affect drive, volition, and attention/memory processes (level 1 BS). ${ }^{9}$ Subsequently, other subtle subjectively perceived symptoms may occur that are more "characteristic" of schizophrenia, and involve perception, thinking, speech, and psychomotor activities (level 2 BS). ${ }^{9}$

In several cases, the emergence of level 1 and level 2 BS is followed by a conversion to FEP, thus substantial research has been devoted to evaluate whether BSc may provide the presupposition for the development of early detection instruments in schizophrenia. BS were operationalized in 178 items within the Bonn scale for the Assessment of Basic Symptoms (BSABS), starting from the Heidelberg checklist. ${ }^{11}$ Subsequently, the Cologne Early Recognition (CER) study identified some characteristic subtle cognitive/perceptive impairments with the highest specificity and predictive power for the assessment of the risk of developing psychosis. ${ }^{12,13}$ These analyses attributed to a shorter version of the BSABS, the Schizophrenia Proneness Instrument (SPI), which allows the detection and assessment of BS in children and youths (SPI-CY) and in adults (SPI-A). ${ }^{12,13}$

Clinical studies have demonstrated that the BS approach is able to differentiate between individuals affected by 
schizophrenia from those suffering from bipolar disorders or depression, as well as from mentally healthy individuals. ${ }^{14-16}$ To ascertain the suitability of the BSc in predicting the development of psychosis, CER analyzed the transition rates of 160 help-seeking individuals during a long-term follow-up period (9.6 years). ${ }^{17}$ Using an initial criterion for the identification of positive cases (presence of at least one of $66 \mathrm{BS}$ ), about $20 \%$ of the positive subjects developed psychosis after 12 months from the first assessment; a further $17 \%$ precipitated into FEP after 2 years; and 13\% became psychotics after the third year. At the end of the study, about
$70 \%$ of the positive cases matched schizophrenia diagnosis within an average of 5.6 years from the initial assessment. Positive subjects who did not develop schizophrenia showed no psychiatric disorders at all or maintained the same signs and symptoms observed in the first examination. ${ }^{17}$

Further analyses evaluated the predictive efficiency of two other BSc-derived criteria for defining at-risk mental states, namely the cognitive-perceptive (COPER) BS risk criterion and the cognitive disturbance (COGDIS) high-risk criterion. ${ }^{17-19}$ COGDIS showed higher specificity and lower sensitivity than COPER (Table 1), suggesting that COGDIS

Table I Reliability of different predictive criteria

\begin{tabular}{|c|c|c|c|c|c|c|c|c|}
\hline Study & $\begin{array}{l}\text { Predictive } \\
\text { approach }\end{array}$ & Criteria & $\begin{array}{l}\text { Follow } \\
\text { up }\end{array}$ & Sensitivity & Specificity & PPV & NPV & Diagnosis (positive cases) \\
\hline $\begin{array}{l}\text { Klosterkötter } \\
\text { et al }{ }^{17}\end{array}$ & BS & $\begin{array}{l}\text { I/66 BS positive } \\
\text { I/I0 COPER }\end{array}$ & $\begin{array}{l}9.6 \pm 7.6 \\
\text { years }\end{array}$ & $\begin{array}{l}0.98 \\
0.78\end{array}$ & $\begin{array}{l}0.39 \\
0.75\end{array}$ & $\begin{array}{l}0.70 \\
0.76\end{array}$ & $\begin{array}{l}0.96 \\
0.77\end{array}$ & Schizophrenia (100\%) \\
\hline $\begin{array}{l}\text { Klosterkötter } \\
\text { et al }{ }^{18}\end{array}$ & BS & $\begin{array}{l}\text { I/I0 COPER } \\
\text { 2/9 COGDIS }\end{array}$ & $\begin{array}{l}9.6 \pm 7.6 \\
\text { years }\end{array}$ & $\begin{array}{l}0.87 \\
0.67\end{array}$ & $\begin{array}{l}0.54 \\
0.83\end{array}$ & $\begin{array}{l}0.65 \\
0.79\end{array}$ & $\begin{array}{l}0.82 \\
0.72\end{array}$ & $\mathrm{~N} / \mathrm{A}$ \\
\hline $\begin{array}{l}\text { Schulze-Lutter } \\
\text { et } \mathrm{al}^{13,16,19}\end{array}$ & BS & I/IO COPER & $\begin{array}{l}20.6 \pm 16.1 \\
\text { months }\end{array}$ & & & 0.36 & & $\begin{array}{l}\text { Schizophrenia (62.5\%), } \\
\text { schizophreniform (I2.5\%), } \\
\text { delusional disorder (12.5\%), } \\
\text { schizoaffective disorder (I2.5\%) }\end{array}$ \\
\hline $\begin{array}{l}\text { Schulze-Lutter } \\
\text { et al }{ }^{13,16,19}\end{array}$ & BS & 2/9 COGDIS & $\begin{array}{l}20.6 \pm 16.1 \\
\text { months }\end{array}$ & & & 0.35 & & $\begin{array}{l}\text { Schizophrenia ( } 86.1 \%) \text {, } \\
\text { schizophreniform }(7.0 \%) \text {, } \\
\text { delusional disorder }(2.3 \%) \text {, } \\
\text { schizoaffective disorder }(2.3 \%) \text {, } \\
\text { major depression }(2.3 \%) \text { with } \\
\text { psychotic features }\end{array}$ \\
\hline Yung et $\mathrm{al}^{21}$ & UHR & $\begin{array}{l}\text { Presence of } 4 \text { or more } \\
\text { predictors }\end{array}$ & 12 months & 0.65 & 0.92 & 0.87 & 0.77 & $\begin{array}{l}\text { Schizophrenia ( } 65.0 \%) \text {, } \\
\text { schizoaffective disorder ( } 5.0 \%) \text {, } \\
\text { psychosis NOS or BPD (I5.0), } \\
\text { bipolar disorders ( } 5.0 \%) \text {, major } \\
\text { depression with psychotic } \\
\text { features (I0.0\%) }\end{array}$ \\
\hline Yung et $\mathrm{al}^{22}$ & UHR & $\begin{array}{l}\text { At least I of the } \\
\text { following predictors: } \\
\text { - trait and state risk } \\
\text { factors + APS positive } \\
\text { - symptoms duration } \\
\quad>5 \text { years } \\
\text { - GAF }<40 \\
\text { - SANS attention }>2\end{array}$ & & 0.6 & 0.93 & 0.81 & 0.82 & $\begin{array}{l}\text { Schizophrenia (55.6\%), } \\
\text { schizoaffective disorder ( } 5.6 \%) \text {, } \\
\text { psychosis NOS or BPD (I I.I), } \\
\text { bipolar disorders (I3.9\%) and } \\
\text { major depression with psychotic } \\
\text { features (I I.I\%), substance- } \\
\text { induced psychotic state (2.8\%) }\end{array}$ \\
\hline Yung et $\mathrm{al}^{23}$ & UHR & CAARMS positive & 6 months & 0.92 & 0.62 & 0.1 & 0.99 & N/A \\
\hline Yung et $\mathrm{al}^{24}$ & UHR & CAARMS positive & 24 months & 0.9 & 0.63 & 0.16 & 0.99 & N/A \\
\hline Nelson et $\mathrm{al}^{27}$ & UHR & CAARMS positive & $\begin{array}{l}\text { I year } \\
3 \text { years } \\
5 \text { years }\end{array}$ & $\begin{array}{l}0.48 \\
0.44 \\
0.45\end{array}$ & $\begin{array}{l}0.83 \\
0.84 \\
0.88\end{array}$ & $\begin{array}{l}0.39 \\
0.52 \\
0.72\end{array}$ & $\begin{array}{l}0.88 \\
0.80 \\
0.69\end{array}$ & $\mathrm{~N} / \mathrm{A}$ \\
\hline Miller et $\mathrm{al}^{26}$ & UHR & SIPS positive & 24 months & 1.00 & 0.73 & 0.62 & & N/A \\
\hline Wood et al ${ }^{28}$ & UHR & SIPS positive & 30 months & 0.89 & 0.6 & & & $\begin{array}{l}\text { Schizophrenia ( } 25.4 \%) \text {, } \\
\text { schizophreniform ( } 20.3 \%) \text {, delusional } \\
\text { disorder }(3.43 \%) \text {, schizoaffective } \\
\text { disorder }(10.2 \%) \text {, psychosis NOS or } \\
\text { BPD ( } 30.5) \text {, bipolar disorders with } \\
\text { psychotic features }(10.2 \%)\end{array}$ \\
\hline
\end{tabular}

Abbreviations: APS, attenuated psychotic symptoms; BS, basic symptoms; CAARMS, Comprehensive Assessment of At-Risk Mental States; COGDIS, cognitive disturbance high-risk criterion; COPER, cognitive-perceptive risk criterion; GAF, Global Assessment of Functioning; NA, not available; SANS, Scale of Assessment for Negative Symptoms; SIPS, Structured Interview for Prodromal Syndromes; UHR, ultra-high risk. 
may be more selective in identifying only individuals at risk of psychosis, at the cost of missing more future converters in the examined sample.

Besides the elevated specificity of COGDIS and COPER, the selection criterion of one to 66 BS first proposed by CER showed very high negative predictive and sensitivity values (above 95\%) during a long-term follow-up (Table 1), indicating that this approach may be the most efficient in excluding the presence of a psychosis prodromal syndrome. ${ }^{17-19}$ However, comparative analyses are necessary to ascertain the selectivity of the different BS criteria in identifying individuals who later develop schizophrenia rather than other psychotic disorders, as well as to evaluate the validity of BSc in different countries and cultures. ${ }^{20}$

\section{The UHR approach}

The UHR approach was specifically developed to identify individuals with the highest probability to develop FEP in a short-term period. The UHR criteria generally take into account three different prodromal features: 1) attenuated positive symptoms; 2) brief intermittent frank psychosis; and 3) genetic risk or recent functional decline. ${ }^{21-24}$ Starting from this approach, Yung et al developed a suitable operationalized instrument, the Comprehensive Assessment of At-Risk Mental States (CAARMS), that incorporates different psychopathological dimensions for a proper risk assessment. ${ }^{25}$ Miller et al validated the Structured Interview for Prodromal Syndromes (SIPS), which includes an analysis of family history, Global Assessment of Functioning (GAF), schizotypal personality, and the Scale of Prodromal Symptoms (SOPS), providing an evaluation of the severity of the prodromal state. ${ }^{26}$ Furthermore, Miller et al operationalized the Criteria of Prodromal Syndromes (COPS), which differs from the CAARMS UHR criteria mostly on the basis of the duration of symptoms. ${ }^{26}$

As expected, clinical studies adopting UHR criteria found significant conversion rates among positive subjects (15\%-50\%), even within the first 1 -year period. ${ }^{21-28}$ The specificity of UHR criteria in predicting psychosis appears to be generally high (Table 1) and in agreement with the purpose to identify only individuals with elevated and immediate risk of developing such mental symptoms. Some clinical studies ${ }^{29,30}$ have shown moderate sensitivity values and a low selectivity in identifying only individuals who later develop schizophrenia rather than other psychotic disorders (Table 1), possibly depending on the adopted UHR predictive criteria. Furthermore, follow-up duration and recruitment procedures may have played a role in determining the transition rates observed in these clinical analyses..$^{29,30}$

\section{Clinical characteristics of individuals at risk of developing psychosis}

Recently, several clinical studies ${ }^{31-38}$ have investigated the neuro- and psychopathological features of individuals selected using UHR criteria. Brain imaging studies found that functional and anatomical abnormalities may occur in different cortical areas (left anterior cingulate and middle temporal gyrus) of UHR individuals even before the outbreak of psychosis. ${ }^{31-33}$ Increased dopamine synthesis and glutamate levels were observed in the basal ganglia of individuals at risk of developing psychosis. ${ }^{34-36}$ Furthermore, subjects with attenuated psychotic symptoms often show modified cortisol levels and increased pituitary and reduced hippocampal volumes, suggesting that a functional alteration of the hypothalamic-pituitary-adrenal axis, and, in general, an enhanced sensitivity to stress, may be relevant factors in determining the vulnerability to psychosis. ${ }^{37,38}$

From a psychopathological point of view, clinical analyses have indicated that the temporal pattern of subthreshold psychotic symptoms may vary greatly among UHR individuals. A long-term follow-up (15 years) indicated that the highest risk of developing psychosis fell within 2 years from the initial assessment; after this point, a progressive reduction of transition rates lasting about 8 years was observed. ${ }^{27}$ Among non-converters, $15 \%-55 \%$ of subjects remitted from initial UHR status, while other patients remained stable or experienced a reduction of attenuated psychotic symptoms over time. ${ }^{39,40}$

Generally, UHR subjects also suffer a wide array of comorbid psychiatric symptoms. Depression, cognitive impairments, anxiety, and cannabis abuse are frequently observed in UHR individuals, ${ }^{41}$ thus several studies are trying to correlate the incidence of these comorbid signs with the risk of developing psychosis. ${ }^{42-43}$ Some psychopathological features of UHR subjects (eg, obsessive-compulsive behavior, cognitive deficits) have already been identified as promising markers of specific trajectories in the evolution of prodromal symptoms. ${ }^{44-46}$ On the other hand, comorbidity often constitutes a confounding variable when assessing the risk of developing psychosis in the clinical practice. ${ }^{47}$

Recently, it has been debated whether UHR and BS criteria may identify populations of individuals at risk of psychosis sharing similar clinical features, since the two strategies were developed starting from different theoretic approaches. From this point of view, it is remarkable that the inclusion of 
BS criteria into UHR-based assessment algorithms identified a more homogeneous sample of clinically and cognitively impaired individuals. ${ }^{48}$ Moreover, recent studies showed that the UHR approach was less selective than BS criteria in discriminating individuals at risk of developing schizophrenia from those who are going to be affected by other psychotic disorders (Table 1) ${ }^{49,50}$ suggesting that the populations of patients selected by the two predictive approaches may partially differ.

It was also investigated whether BS may occur earlier in the prodromal phase than the subthreshold psychotic symptoms identified by the UHR criteria. A recent retrospective analysis found that such a sequence of prodromal signs can be detected in individuals with a high school-leaving certificate, but not among schizophrenic patients with a low educational background. ${ }^{51}$ Thus, it appears feasible that sociocultural and socioeconomic factors may have a role in modulating the evolution of the disease, and that UHR and BS criteria may possess different abilities to identify peculiar psychopathological patterns.

\section{New risk-assessment approaches: multivariate marker analyses and risk staging models}

The BS and UHR approaches have provided suitable tools for proper assessment of the risk of developing FEP, but some problems that may have a profound impact in clinical practice still remain unresolved. An analysis of the data depicted in Table 1 indicates the presence of an inverse correlation between the sensitivity and specificity of the different predictive criteria. A similar trend was also shown in a recent systematic review. ${ }^{20}$

From the therapeutic point of view, the relationship between specificity and sensitivity entails relevant clinical and ethical issues, since practitioners have to evaluate whether to enroll only some individuals with the highest risk of developing psychosis into their prevention programs or switch to less precise selection criteria that, in turn, allow the identification of the majority of future converters.

In this regard, the use of multivariate analyses of empirically derived markers may constitute a valuable strategy by which to modify the balance between sensitivity and specificity of predictive criteria. ${ }^{21}$ Accordingly, the North American Prodrome Longitudinal Study (NAPLS) consortium has recently found that empirically derived markers were able to modify the sensitivity/specificity ratio of UHR predictive criteria when combined into multivariate algorithms.$^{52}$ Furthermore, one of the first Personal Assessment and Crisis Evaluation (PACE) clinic studies evaluating different combinations of a variety of potential predictors found that a screening procedure based on the presence of four or more predictors provides adequate specificity (91\%), sensitivity (86\%), and negative predictive values (94\%) at 6-month follow-up. Most importantly, the use of multivariate analyses may allow the inclusion of both psychometric and biological markers within the same algorithm, with possible benefits in terms of sensitivity and specificity of predictive criteria.

Starting from ethical and practical issues, the reliability of one-threshold criteria in discriminating between individuals who are at risk and not at risk of developing psychosis has also been discussed. Clinical studies have shown that the progression of the disease is often characterized by fluctuations of prodromal symptom intensity, until a full-blown psychosis can be clearly diagnosed or excluded. ${ }^{27,39,40}$ From this point of view, one-threshold criteria appear to provide only a static or short-term picture of the symptomatic pattern of UHR individuals, which may be insufficient for a proper risk assessment. Nevertheless, such an in-out approach may exacerbate problems relating to the sensitivity/specificity of predictive criteria, and it may possibly contribute to the negative effect of labeling on stigmatization.

To overcome these problems, it was hypothesized that repeated assessments of the help-seeking individuals' clinical conditions from the very early phases of risk could be a useful strategy by which to enrich the sample of future converters and increase the chance of avoiding false positives. Furthermore, the necessity to identify different stages of the progression of disease, from the early signs of risk to the appearance of the severe and persistent phase of the illness, so that intervention and prevention strategies may be properly applied according to the clinical status of the patient, has been emphasized..$^{53}$

In line with this approach, the German Research Network on Schizophrenia (GRNS) has developed a risk staging model to be considered for adequate classification and monitoring of individuals at risk of developing psychosis. ${ }^{17,54}$ This model takes into account that FEP is often preceded by a sequence of syndrome stages, in which low specific signs of an "early atrisk psychosis state" are followed by the emergence of BS and attenuated psychotic symptoms that are characteristic of the "late at-risk psychosis state" until the transition to psychosis. Starting from these considerations, CER has proposed new criteria to discriminate among different risk mental states, ${ }^{17,54}$ also suggesting possible differentiated prevention therapies for early at-risk psychosis state and late at-risk psychosis state, such as psychological therapy and pharmacological interventions, respectively. ${ }^{4,17,54-56}$ 
Furthermore, the European Prediction of Psychosis Study (EPOS) has proposed a two-step procedure in which help-seeking individuals are first screened using both UHR and COGDIS criteria and then classified using a prognostic index based on six empirically derived variables highly predictive of transition to psychosis. ${ }^{49}$ The final model allows for stratification of the sample into four classifications of risk, thus moving from a one-threshold approach to a more continuous risk estimation. ${ }^{49}$

A new, promising line of research is also investigating the possibility of discriminating between UHR individuals that develop schizophrenia from those who are going to be affected by other psychiatric disorders. Brain imaging analyses highlighted that a decreased volume of parietal, middle temporal, and inferior frontal cortex could be recorded frequently in UHR individuals who develop schizophrenia, while smaller subcallosal cingulate volume was preferentially observed in those who are later affected by affective psychoses. ${ }^{57}$ Furthermore, reductions of amygdala and insula volumes were evident in UHR individuals who developed bipolar disorders. ${ }^{58} \mathrm{~A}$ recent study indicated that olfactory identification impairment could be a selective marker of transition to schizophrenia, possibly because the incipient onset of psychosis precociously affects frontal lobe development in schizophrenia, but not in other psychotic disorders. ${ }^{59}$ Recently, a preliminary naturalistic study indicated that progression to schizophrenia or schizoaffective disorder was associated with the absence of anxiety disorders and poor executive functioning, while conversion to bipolar disorders with or without psychotic features relied on the presence of anxiety disorders. ${ }^{60}$ Finally, very recent findings are providing evidence that clinical and behavioral data can be combined for a proper identification of help-seeking young individuals who may develop bipolar disorder ${ }^{61}$ a mental pathology that is often diagnosed in subjects previously considered to be at UHR of developing psychosis (Table 1).

\section{Prevention strategies}

In recent years, the availability of reliable predictive psychometric scales has strongly stimulated the research on the prevention of FEP. Previous studies ${ }^{1-3}$ have indicated that atypical antipsychotic and antidepressant drugs may ameliorate the clinical outcome of schizophrenic patients, thus these pharmacological interventions have been tested in individuals at risk of developing psychosis. Furthermore, the efficacy of psychological and nutraceutical interventions has been assessed, ${ }^{88}$ taking into account that these approaches may provide benefits in terms of symptom control and cognitive functioning. These prevention strategies are still under investigation, but it is already clear that two issues are particularly relevant for their applicability in the clinical practice. The first issue deals with the efficacy/tolerability profiles of the different intervention strategies, which should be addressed in a framework of prognosis, rather than of diagnosis. Moreover, it appears particularly relevant to evaluate whether these intervention strategies may simply delay the occurrence of FEP or if they are really able to prevent the development of psychotic disorders.

\section{Pharmacological approaches}

Recent clinical studies have investigated the efficacy of different drug therapies in preventing the development of psychosis. ${ }^{62-79}$ In a PACE randomized trial, UHR individuals treated with a combination of up to $2 \mathrm{mg}$ risperidone plus cognitively oriented psychotherapy (SPI group) were compared with those receiving need-based intervention (NBI group) ${ }^{62}$ At the end of the 6-month treatment, the percentage of participants who progressed to FEP was significantly lower in the SPI group (9.7\%) than in the NBI group (35.7\%). However, this difference was no longer evident 6 months after treatment cessation, ${ }^{62}$ nor could significant differences between the two groups be observed after $3-4$ years of drug withdrawal. ${ }^{63}$ Considering that the study design did not include some experimental control groups, the relative contribution of the atypical antipsychotic medication could not be distinguished from that of the cognitively oriented therapy. This limitation was addressed in a recent double-blind, randomized, placebocontrolled trial in which the effects of cognitively oriented therapy plus risperidone, cognitively oriented therapy plus placebo, and supportive therapy plus placebo were compared in UHR individuals. The study indicated that no statistically significant differences could be detected among the three experimental groups in terms of transition rates, negative symptoms, and overall functioning. ${ }^{64,65}$

In North America, the Prevention through Risk Identification Management and Education (PRIME) study compared the transition rates of a 12-month treatment with olanzapine (5-15 mg daily) or placebo. ${ }^{66}$ At the end of the treatment phase, $16 \%$ of the UHR individuals treated with olanzapine and $38 \%$ of the placebo group converted to psychosis, but the difference between transition rates did not reach statistical significance ${ }^{66}$ Moreover, increased conversion rates and subthreshold symptom exacerbation were observed in the olanzapine group after 1 year of drug withdrawal, suggesting that this antipsychotic therapy may delay, but not prevent, the appearance of FEP. ${ }^{66}$ 
In respect to the possibility that atypical antipsychotic drugs may ameliorate the symptoms affecting help-seeking individuals at the prodromal phase, the available data suggested that improvements in functional deficits and positive and negative symptoms may possibly be induced by atypical antipsychotics such as risperidone, olanzapine, amisulpride, and aripiprazole, ${ }^{63-69}$ however, further studies are needed to better ascertain the balance between efficacy and tolerability of these therapeutic strategies, also considering that two recent meta-analyses highlighted that the evidence on the possible benefits induced by antipsychotic prevention therapies is still inconclusive. ${ }^{70,71}$ Furthermore, an elevated incidence of weight gain and hyperprolactinemia was observed in UHR individuals treated with olanzapine and amisulpride, respectively. ${ }^{66,67}$ These side effects are known to induce distress and low drug compliance among adolescents, ${ }^{72,73}$ also possibly interfering with youths' sexual and physical development. ${ }^{74,75}$

Conflicting results were also provided by clinical trials exploring the efficacy of antidepressant drugs in preventing psychosis. ${ }^{76-78} \mathrm{~A}$ first naturalistic study indicated that no conversion to psychosis could be detected in 20 prodromal patients receiving antidepressant therapies, while $43 \%$ of patients treated with antipsychotic drugs developed a fullblown psychosis over the next 2 years. ${ }^{76} \mathrm{~A}$ second retrospective naturalistic study found that $8 \%$ of UHR individuals treated with antidepressant drugs became psychotic in the following 2 years, while $29 \%$ of patients who received antipsychotic drugs subsequently developed psychosis. ${ }^{77}$ Finally, a third large naturalistic and multicenter analysis highlighted that antidepressant therapy was not associated with a significant reduction of symptom severity, whereas antipsychotic administration produced a decline in positive and disorganized symptoms of individuals in the prodromal phase. $^{78}$

Recently, a proton magnetic resonance spectroscopy analysis has also investigated the effects induced by low-dose lithium when administered to UHR subjects, highlighting that lithium may better protect the hippocampal microstructure in UHR-treated individuals when compared with supportive standard treatment. ${ }^{79}$

To date, no studies have provided clear evidence indicating that the proposed pharmacological therapies may prevent the development of the brain alterations or cognitive decline observed in schizophrenic individuals. Similarly, it is still unclear whether these drugs may affect normal brain development processes when administered to UHR individuals. Furthermore, whether pharmacological treatments may drive the natural course of the disease towards other mental pathologies should be investigated, since an unexpectedly high incidence of depression with psychotic features was observed in UHR individuals receiving antipsychotic therapy. ${ }^{62}$

\section{Psychological interventions}

It is well established that adjunct psychological interventions may improve global and social functioning of individuals affected by schizophrenia ${ }^{80}$ with possible long-term benefits in terms of patient quality of life, family burden, and drug treatment adherence. ${ }^{81}$ Some clinical analyses have also indicated that psychological interventions may reduce the severity of psychotic symptoms and relapse in schizophrenic individuals, thus the efficacy and tolerability of this therapeutic approach was explored in individuals at risk of developing psychosis. ${ }^{81}$

With this in mind, a recent randomized trial evaluated the effect induced by 6 months' cognitive therapy (CT) or treatment as usual (TAU) in help-seeking UHR individuals. ${ }^{82}$ The results indicated that $\mathrm{CT}$ significantly ameliorated the intensity of attenuated psychotic symptoms and prevented transition to psychosis over 12 months..$^{82}$ Furthermore, the intervention group found that CT significantly reduced the likelihood of being prescribed an antipsychotic medication and of making progression to psychosis (as defined on the Positive and Negative Syndrome Scale [PANSS] after controlling for baseline cognitive factors), after 3 years of treatment cessation. The low withdrawal rates led researchers to conclude that CT was well-tolerated by UHR individuals. ${ }^{82,83}$

A recent randomized controlled trial compared the effects induced by cognitive behavioral therapy (CBT) and supportive counseling in 67 prodromal individuals. The results indicated that both psychological interventions were associated with significant improvements in global and social functioning and were well tolerated. ${ }^{84}$ Comparable results were also found in other clinical analyses comparing the conversion rates of UHR individuals receiving CBT or supportive counseling. ${ }^{65,85}$

A further randomized controlled clinical trial tested the effects of a new CBT specifically designed for UHR patients who also received TAU. Compared with only TAU, the new CBT induced favorable effects on both transition rates and subthreshold psychotic symptom intensity, ${ }^{86}$ supporting the hypothesis that therapies targeted for the specific clinical features of UHR individuals may improve the efficacy of psychological interventions. Most importantly, a 12-month randomized multicenter trial, enrolling only help-seeking outpatients in the early initial prodromal state, found that an 
integrated psychological intervention (individual CBT plus group skills training plus cognitive remediation plus psychoeducational multifamily groups) was superior to supportive counseling in preventing progression to psychosis. ${ }^{55}$ Such effect was sustained at 12- and 24-month follow-up, ${ }^{55}$ suggesting that psychological interventions may be particularly effective in preventing psychosis when the disease is counteracted from a very early phase and different aspects of patient daily life are taken into consideration.

\section{Natural compounds}

It has often been hypothesized that nutrient deficiencies or imbalances may be partially responsible for the development of neuropsychiatric disorders. ${ }^{87}$ Recently, several studies have focused on the effects induced by long-chain omega-3 polyunsaturated fatty acids (PUFAs) in individuals at risk of developing psychosis. A double-blind, randomized, placebocontrolled trial found that a 12-week omega-3 PUFA treatment significantly reduced the transition to psychosis in UHR individuals when compared to placebo, at 12-week follow up. ${ }^{88}$ Furthermore, significant improvements of PANSS and GAF scores and no evident side effects were recorded in the omega-3 PUFA treatment group. ${ }^{88}$ A 12 -month follow-up of this study confirmed the low transition rates of UHR individuals treated with omega-3 PUFAs, highlighting that this experimental group also experienced a reduction of attenuated positive, negative, and general psychopathological symptoms. ${ }^{89,90}$

A further post hoc analysis investigated the efficacy of omega-3 PUFAs over time. The results indicated that omega-3 PUFA supplementation induced a significant reduction of PANSS total and general psychopathology subscale scores in UHR individuals after the first 4 weeks of treatment, while lower mean PANSS positive scores could be detected after 8 weeks. ${ }^{91}$ Finally, significant improvements in negative symptoms and GAF scores were recorded after 12 weeks of omega-3 PUFA treatment. ${ }^{91}$

The possibility that omega-3 PUFAs may improve GAF scores without relevant side effects was also proposed by a recent sub-analysis involving UHR adolescents with borderline personality disorder. ${ }^{92}$ Interestingly, this study found that erythrocyte omega-3 levels at baseline correlated positively with psychosocial functioning, and negatively with psychopathology scores, in the examined subjects..$^{92}$ Furthermore, it was found that omega-3 PUFAs normalized intracellular phospholipase A2 activity and $\delta$-6-desaturase-mediated metabolism of omega-3 and omega-6 PUFAs, suggesting a possible role of these natural compounds in the neuroprogression of psychosis. ${ }^{93}$
It should be noted, however, that omega-3 PUFA supplementations did not induce any change in the electroencephalographic deficits that were associated with negative symptoms of UHR individuals who transitioned to psychosis. ${ }^{94}$ Moreover, recent meta-analyses claimed that further high-quality replications of the available results are needed to confirm the effectiveness of omega-3 PUFAs in preventing the development of psychosis..$^{70,71,95}$

Other natural compounds are currently under investigation to evaluate their ability to prevent psychosis. Recently, two short-term pilot studies investigated the effects induced by administration of glycine in UHR individuals, taking into account that N-methyl-D-aspartic acid glycine-site agonists may possibly modulate prodromal symptoms of psychosis. ${ }^{96}$ The results of these analyses led the authors to hypothesize that glycine treatments could be associated with symptom reduction and a possible improvement in cognitive function. ${ }^{96}$

At preclinical level, it has been suggested that several compounds may counteract brain maldevelopmental or degenerative processes possibly occurring in schizophrenia. Among these natural compounds, cerebrolysin and erythropoietin prevented the occurrence of the behavioral and brain morphological alterations observed in animal models of schizophrenia. ${ }^{97-99}$

\section{Discussion}

In reviewing this literature, it is evident that a tremendous effort has been made to increase the chances of correctly predicting the development of FEP. Both the BS and UHR approaches have provided interesting theoretic bases for a proper characterization of the clinical features of prodromalphase psychosis. Significant advances have also been made in improving the effectiveness of predictive scales and criteria designed to assess the risk of FEP. Most of all, the recent development of empirically based algorithms and risk staging models offers new perspectives by which to overcome some limits of previous one-threshold risk-assessment procedures, providing flexible tools for monitoring the clinical status of patients from an early at-risk psychosis state.

On the other hand, research on new therapeutic tools targeted for psychosis prevention has not made such a rapid advance. Antipsychotics, lithium, and antidepressant drugs were identified many years ago as useful agents for the symptomatic treatment of severe mental diseases; however, the efficacy/tolerability profiles of these drugs should be carefully considered when administered to young individuals at risk of developing psychosis. To date, clinical trials do not provide conclusive evidence indicating that these drugs may 
reduce FEP incidence. Moreover, it remains unclear whether these pharmacological tools may affect psychological and physical maturation processes occurring during adolescence and early adulthood. Further studies are also needed to better characterize the effects induced by natural compounds and psychological interventions in individuals at risk of developing psychosis. Although these therapeutic approaches appear to be promising and well tolerated, further high-quality and exhaustive clinical analyses should be carried out in order to confirm their long-lasting efficacy in preventing FEP.

The uncertain etiology of psychotic disorders has surely complicated the development of new instruments able to predict or prevent such mental disturbance, possibly explaining some ethical and clinical doubts on the present status of the research. However, a continuous, meticulous, and sometimes accidental matching between patient symptoms and response to therapeutic interventions has brought unexpected progress in psychiatry research. Thus, it is expected that this approach may increase the chances of developing adequate prevention programs for individuals at risk of developing psychosis when different opportunities and directions of research are explored.

\section{Prediction}

The relative paucity of prevention strategies specifically designed for individuals at risk of developing psychosis stimulates some reflection on the concept of attenuated psychosis syndrome. In the last few decades, research on UHR individuals has progressively conceptualized this syndrome in terms of risk of developing a specific typology of psychiatric disturbance (psychotic symptoms), notwithstanding that the appearance of subtle psychotic signs often represents the prodromal phase of mental pathologies characterized by different symptoms and outcomes. UHR individuals often receive different diagnoses after FEP, varying from schizophrenia to depression and bipolar and personality disorders. These mental diseases are successfully treated using different therapeutic approaches. Thus, it cannot be excluded that the efficacy of the proposed prevention strategies may depend on the mental pathology that is going to affect the patient, possibly explaining some conflicting results provided by clinical trials.

The achievability of predicting the appearance of specific mental pathologies is far from being unrealistic. Gross and Huber ${ }^{9}$ developed the BSc with the purpose of classifying peculiar psychopathological basic signs of schizophrenia. Consistently, clinical studies adopting BS criteria found that most of the converters developed this mental pathology. The UHR approach also possesses the potential to discriminate among individuals at risk of developing different psychotic pathologies, and an independent risk syndrome for psychosis related to $22 \mathrm{q} 11.2$ deletion syndrome or schizotypal personality disorder was recently identified using SIPS. ${ }^{100}$ Most importantly, promising results have been achieved in the attempt to identify selective neuro- and psychopathological predictors of different mental diseases. Thus, it is feasible that the available selection criteria may be combined or modified to facilitate a differential prognosis in individuals at risk of developing psychosis, with possible benefits in terms of matching prognosis/ diagnosis and therapy in the next few years.

A further chance to improve the efficacy of predictive criteria may come from the analysis of prodromal symptomatic patterns. It is well known that the outcome of schizophrenia varies greatly among individuals affected by this mental disease. Some patients show a rapid and dramatic decline of cognitive function within the first years after FEP, whereas symptom intensity of other schizophrenic individuals is rather stable. Furthermore, Andreasen et al have recently proposed new criteria for evaluating remission states in schizophrenic individuals who show an evident symptom recovery. ${ }^{101}$

Similar symptomatic patterns were also observed in UHR individuals, providing an opportunity to better evaluate the cost/benefits of prevention therapies. To this regard, the predictive efficacy of empirically derived algorithms may take advantage of the recently identified psychopathological and instrumental markers linking the prodromal features of psychosis with the outcome of the disease. Furthermore, the recently proposed risk staging models may provide an opportunity for monitoring patient mental conditions and differentiating therapies, depending on the appearance and patterns of prodromal signs. One of the main advantages of risk staging models is, indeed, the detection of the very early risk signs of mental disturbance. This new approach basically reverses the strategy of UHR criteria that aimed to identify individuals at imminent risk of developing psychosis, but aligns psychiatric prevention programs with those of other branches of medicine in which a very early risk detection is highly recommended to reduce the impact of risk factors, properly evaluate the evolution of the disease, and facilitate the adoption of intervention strategies with improved efficacy/tolerability profiles. In our opinion, empirically derived algorithms and risk staging models (or their combination) are therefore the most promising strategies to improve the predictive power and reliability of psychometric scales.

\section{Prevention}

To date, the literature seems to delineate some possible clinical targets and future developments of the available 
prevention strategies. The rationale of omega-3 PUFA therapy suggests that this approach may be particularly indicated for UHR individuals showing omega-3 deficits or an evident psychopathological decline. Recently, poor functional outcome was associated with specific neurocognitive decrements in youth individuals, regardless of transition to psychosis. Furthermore, a progressive worsening of different subclinical symptoms was also observed in non-converters. If the positive results of recent clinical trials are confirmed, it is expected that the therapeutic spectrum of natural compounds will shortly include help-seeking individuals with a prognosis different from psychosis.

Psychologists have already developed protocols specifically designed for individuals at risk of developing psychosis and, in general, the efficacy of these psychotherapies is supposed to rapidly improve in the next few years. The limits of these approaches are possibly related to the residual affective, cognitive, and social resources of clients, as well as to their motivation to attend and engage in therapy. However, the development of targeted and integrated psychological interventions may potentially contribute to overcoming such limitations, acting on the family and social environment to reduce disabilities and stressors of individuals at risk of developing psychosis.

The use of pharmacological drugs in prevention therapy has often been questioned on the basis of cost/benefit and ethical issues, particularly when antipsychotic therapies were taken into consideration for the treatment. Psychologists have already developed protocols specifically of UHR individuals. In some circumstances, the intensity of prodromal symptoms may possibly justify a pharmacological approach. In our opinion, however, a large use of these prevention therapies is not only limited by their side effect profiles and uncertain efficacy in preventing FEP, but also complicated by the fact that the pharmacological activity of these drugs is mostly directed against the symptomatic features of mental diseases. It is generally puzzling to evaluate whether remission states observed in psychotic individuals are due to the efficacy of the drug therapy or represent a spontaneous evolution of the disease. These clinical and ethical doubts are even more dramatic when patients have not yet received a definitive diagnosis, and subthreshold symptoms should be monitored to properly apply inclusion, exclusion, and exit criteria of prevention programs.

\section{Conclusion}

The decision to include the "attenuated psychosis symptoms" in the appendix of the DSM-V has possibly provided a chance to better address the complex relationships link- ing the mental status of help-seeking individuals at risk of developing psychosis with the identification of adequate prevention strategies.

\section{Disclosure}

The authors report no conflicts of interest in this work.

\section{References}

1. Yung AR, Woods SW, Ruhrmann S, et al. Whither the attenuated psychosis syndrome? Schizophr Bull. 2012;38(6):1130-1134.

2. Ruhrmann S, Klosterkötter J, Bodatsch M, et al. Pharmacological prevention and treatment in clinical at-risk states for psychosis. Curr Pharm Des. 2012;18(4):550-557.

3. Lieberman JA, Perkins D, Belger A, et al. The early stages of schizophrenia: speculations on pathogenesis, pathophysiology, and therapeutic approaches. Biol Psychiatry. 2001;50(11):884-897.

4. Ruhrmann S, Schultze-Lutter F, Klosterkötter J. Early detection and intervention in the initial prodromal phase of schizophrenia. Pharmacopsychiatry. 2003;36 Suppl 3:S162-S167.

5. Lieberman JA, Perkins DO, Jarskog LF. Neuroprotection: a therapeutic strategy to prevent deterioration associated with schizophrenia. CNS Spectr. 2007;12(3 Suppl 4):1-13.

6. Catts VS, Fung SJ, Long LE, et al. Rethinking schizophrenia in the context of normal neurodevelopment. Front Cell Neurosci. 2013;7:60.

7. Fusar-Poli P, Borgwardt S, Bechdolf A, et al. The psychosis high-risk state: a comprehensive state-of-the-art review. JAMA Psychiatry. 2013;70(1):107-120.

8. American Psychiatric Association. Diagnostic and statistical manual of mental disorders. 5th ed (DSM-5) Washington, DC: American Psychiatric Publishing; 2013

9. Gross G, Huber G. The history of the basic symptom concept. Acta Clin Croat. 2010;49:47-59.

10. Gross G, Huber G, Schüttler R. Computerized tomography studies on schizophrenic diseases. Arch Psychiatr Nervenkr. 1982;231: 519-526.

11. Gross G, Huber G, Klosterkötter J, Linz M. BSABS: Bonner Skala für die Beurteilung von Basissymptomen [BSABS: Bonn Scale for the Assessment of Basic Symptoms]. New York, NY, USA: Springer-Verlag; 1987. German.

12. Fux L, Walger P, Schimmelmann BG, Schultze-Lutter F. The Schizophrenia Proneness Instrument, Child and Youth version (SPI-CY): practicability and discriminative validity. Schizophr Res. 2013;146(1-3):69-78.

13. Schultze-Lutter F, Addington J, Ruhrmann S, Klosterkötter J. Schizophrenia Proneness Instrument: Adult Version (SPI-A). Rome: Giovanni Fioriti Editore; 2007.

14. Klosterkötter J, Ebel H, Schultze-Lutter F, Steinmeyer EM. Diagnostic validity of basic symptoms. Eur Arch Psychiatry Clin Neurosci. 1996;246(3):147-154.

15. Parnas J, Handest P, Saebye D, Jansson L. Anomalies of subjective experience in schizophrenia and psychotic bipolar illness. Acta Psychiatr Scand. 2003;108(2):126-133.

16. Schultze-Lutter F, Ruhrmann S, Picker H, von Reventlow HG, Brockhaus-Dumke A, Klosterkötter J. Basic symptoms in early psychotic and depressive disorders. Br J Psychiatry Suppl. 2007;51:s31-s37.

17. Klosterkötter J, Hellmich M, Steinmeyer EM, Schultze-Lutter F. Diagnosing schizophrenia in the initial prodromal phase. Arch Gen Psychiatry. 2001;58(2):158-164.

18. Klosterkötter J, Schultze-Lutter F, Bechdolf A, Ruhrmann S. Prediction and prevention of schizophrenia: what has been achieved and where to go next? World Psychiatry. 2011;10(3):165-174.

19. Schultze-Lutter F, Klosterkötter J, Picker H, Steinmeyer EM, Ruhrmann S. Predicting first-episode psychosis by basic symptoms. Clin Neuropsychiatry. 2007;4:11-22. 
20. Chuma J, Mahadun P. Predicting the development of schizophrenia in high-risk populations: systematic review of the predictive validity of prodromal criteria. Br J Psychiatry. 2011;199(5):361-366.

21. Yung AR, Phillips LJ, Yuen HP, et al. Psychosis prediction: 12-month follow up of a high-risk ("prodromal") group. Schizophr Res. 2003;60(1):21-32.

22. Yung AR, Phillips LJ, Yuen HP, McGorry PD. Risk factors for psychosis in an ultra high-risk group: psychopathology and clinical features. Schizophr Res. 2004;67(2-3):113-142.

23. Yung AR, Stanford C, Cosgrave E, et al. Testing the Ultra High Risk (prodromal) criteria for the prediction of psychosis in a clinical sample of young people. Schizophr Res. 2006;84(1):57-66.

24. Yung AR, Nelson B, Stanford C, et al. Validation of "prodromal" criteria to detect individuals at ultra high risk of psychosis: 2 year follow-up. Schizophr Res. 2008;105(1-3):10-17.

25. Yung AR, Yuen HP, McGorry PD, et al. Mapping the onset of psychosis: the Comprehensive Assessment of At-Risk Mental States. Aust N Z J Psychiatry. 2005;39(11-12):964-971.

26. Miller TJ, McGlashan TH, Rosen JL, et al. Prodromal assessment with the structured interview for prodromal syndromes and the scale of prodromal symptoms: predictive validity, interrater reliability, and training to reliability. Schizophr Bull. 2003;29(4):703-715.

27. Nelson B, Yuen HP, Wood SJ, et al. Long-term follow-up of a group at ultra high risk ("prodromal") for psychosis. The PACE 400 Study. JAMA Psychiatry. 2013;70(8):793-802.

28. Woods SW, Addington J, Cadenhead KS, et al. Validity of the prodromal risk syndrome for first psychosis: findings from the North American Prodrome Longitudinal Study. Schizophr Bull. 2009;35(5):894-908.

29. Rietdijk J, Klaassen R, Ising H, et al. Detection of people at risk of developing a first psychosis: comparison of two recruitment strategies. Acta Psychiatr Scand. 2012;126(1):21-30.

30. Yung AR, Yuen HP, Berger G, et al. Declining transition rate in ultra high risk (prodromal) services: dilution or reduction of risk? Schizoph Bull. 2009;35(3):894-908

31. Koike S, Takizawa R, Nishimura Y, et al. Different hemodynamic response patterns in the prefrontal cortical sub-regions according to the clinical stages of psychosis. Schizophr Res. 2011;132(1):54-61.

32. Meijer JH, Schmitz N, Nieman DH, et al. Semantic fluency deficits and reduced grey matter before transition to psychosis: a voxelwise correlational analysis. Psychiatry Res. 2011;194(1):1-6.

33. Ziermans TB, Schothorst PF, Schnack HG, et al. Progressive structural brain changes during development of psychosis. Schizophr Bull. 2012;38(3):519-530

34. Egerton A, Chaddock CA, Winton-Brown TT, et al. Presynaptic striatal dopamine dysfunction in people at ultra-high risk for psychosis: findings in a second cohort. Biol Psychiatry. 2013;74(2):106-112.

35. Bauer M, Praschak-Rieder N, Kasper S, Willeit M. Is dopamine neurotransmission altered in prodromal schizophrenia? A review of the evidence. Curr Pharm Des. 2012;18(12):1568-1579.

36. de la Fuente-Sandoval C, León-Ortiz P, Favila R, et al. Higher levels of glutamate in the associative-striatum of subjects with prodromal symptoms of schizophrenia and patients with first-episode psychosis. Neuropsychopharmacology. 2011;36(9):1781-1791.

37. Pruessner M, Béchard-Evans L, Boekestyn L, Iyer SN, Pruessner JC, Malla AK. Attenuated cortisol response to acute psychosocial stress in individuals at ultra-high risk for psychosis. Schizophr Res. 2013;146(1-3):79-86.

38. Aiello G, Horowitz M, Hepgul N, Pariante CM, Mondelli V. Stress abnormalities in individuals at risk for psychosis: a review of studies in subjects with familial risk or with "at risk" mental state. Psychoneuroendocrinology. 2012;37(10):1600-1613.

39. Addington J, Cornblatt BA, Cadenhead KS, et al. At clinical high risk for psychosis: outcome for nonconverters. Am J Psychiatry. 2011;168(8): 800-805.

40. Simon AE, Velthorst E, Nieman DH, Linszen D, Umbricht D, de Haan L Ultra high-risk state for psychosis and non-transition: a systematic review. Schizophr Res. 2011;132(1):8-17.
41. Rosen JL, Miller TJ, D’Andrea JT, McGlashan TH, Woods SW. Comorbid diagnoses in patients meeting criteria for the schizophrenia prodrome. Schizophr Res. 2006;85(1-3):124-131.

42. Salokangas RKR, Ruhrmann S, von Reventlow HG, et al; EPOS group. Axis I diagnoses and transition to psychosis in clinical high-risk patients EPOS project: prospective follow-up of 245 clinical high-risk outpatients in four countries. Schizophr Res. 2012;138(2-3):192-197.

43. Piskulic D, Addington J, Cadenhead KS, et al. Negative symptoms in individuals at clinical high-risk of psychosis. Psychiatry Res. 2012;196(2-3):220-234.

44. Fontenelle LF, Lin A, Pantelis C, Wood SJ, Nelson B, Yung AR. Markers of vulnerability to obsessive-compulsive disorder in an ultra-high risk sample of patients who developed psychosis. Early Interv Psychiatry. 2012;6(2):201-206.

45. Corcoran C, Davidson L, Sills-Shahar R, et al. A qualitative research study of the evolution of symptoms in individuals identified as prodromal to psychosis. Psychiatr Q. 2003;74(4):313-332.

46. Schultze-Lutter F, Ruhrmann S, Hoyer C, Klosterkötter J, Leweke FM. The initial prodrome of schizophrenia different duration, different underlying deficits? Compr Psychiatry. 2008;48(5):479-488.

47. O’Donoghue B, Lyne J, Renwick L, et al. A descriptive study of 'noncases' and referral rates to an early intervention for psychosis service. Early Interv Psychiatry. 2012;6(3):276-282.

48. Simon AE, Dvorsky DN, Boesch J, et al. Defining subjects at risk for psychosis: a comparison of two approaches. Schizophr Res. 2006;81(1): 83-90.

49. Ruhrmann S, Schultze-Lutter F, Salokangas RK, et al. Prediction of psychosis in adolescents and young adults at high risk: results from the prospective European prediction of psychosis study. Arch Gen Psychiatry. 2010;67(3):241-251.

50. Fusar-Poli P, Bechdolf A, Taylor MJ, et al. At risk for schizophrenic or affective psychoses? A meta-analysis of DSM/ICD diagnostic outcomes in individuals at high clinical risk. Schizophr Bull. 2013;39(4):923-932.

51. Schultze-Lutter F, Ruhrmann S, Berning J, Maier W, Klosterkötter J. Basic symptoms and ultrahigh risk criteria: symptom development in the initial prodromal state. Schizophr Bull. 2010;36(1):182-191.

52. Thompson A, Nelson B, Yung A. Predictive validity of clinical variables in the "at risk" for psychosis population: international comparison with results from the North American Prodrome Longitudinal Study. Schizophr Res. 2011;126(1-3):51-57.

53. McGorry PD, Nelson B, Goldstone S, Yung AR. Clinical staging: a heuristic and practical strategy for new research and better health and social outcomes for psychotic and related mood disorders. Can J Psychiatry. 2010;55(8):486-497.

54. Ruhrmann S, Schultze-Lutter F, Maier W, Klosterkötter J. Pharmacological intervention in the initial prodromal phase of psychosis. Eur Psychiatry. 2005;20(1):1-6.

55. Bechdolf A, Wagner M, Ruhrmann S, et al. Preventing progression to first-episode psychosis in early initial prodromal states. Br JPsychiatry. 2012;200(1):22-29.

56. BechdolfA, Müller H, Stützer H, et al; PREVENT study group. Rationale and baseline characteristics of PREVENT: a second-generation intervention trial in subjects at-risk (prodromal) of developing firstepisode psychosis evaluating cognitive behavior therapy, aripiprazole, and placebo for the prevention of psychosis. Schizophr Bull. 2011;37 Suppl 2:S111-S121.

57. Dazzan P, Soulsby B, Mechelli A, et al. Volumetric abnormalities predating the onset of schizophrenia and affective psychoses: an MRI study in subjects at ultra high risk of psychosis. Schizophr Bull. 2012;38(5):1083-1091.

58. Bechdolf A, Wood SJ, Nelson B, et al. Amygdala and insula volumes prior to illness onset in bipolar disorder: a magnetic resonance imaging study. Psychiatry Res. 2012;201(1):34-39.

59. Brewer WJ, Wood SJ, McGorry PD, et al. Impairment of olfactory identification ability in individuals at ultra-high risk for psychosis who later develop schizophrenia. Am J Psychiatry. 2003;160(10):1790-1794. 
60. Correll CU, Smith CW, Auther AM, et al. Predictors of remission, schizophrenia, and bipolar disorder in adolescents with brief psychotic disorder or psychotic disorder not otherwise specified considered at very high risk for schizophrenia. J Child Adolesc Psychopharmacol. 2008;18(5):475-490.

61. Bechdolf A, Nelson B, Cotton SM, et al. A preliminary evaluation of the validity of at-risk criteria for bipolar disorders in help-seeking adolescents and young adults. J Affect Disord. 2010;127(1-3):316-320.

62. McGorry PD, Yung AR, Phillips LJ, et al. Randomized controlled trial of interventions designed to reduce the risk of progression to first-episode psychosis in a clinical sample with subthreshold symptoms. Arch Gen Psychiatry. 2002;59(10):921-928.

63. Phillips LJ, McGorry PD, Yuen JP, et al. Medium term follow-up of a randomized controlled trial of interventions for young people at ultra high risk of psychosis. Schizophr Res. 2007;96(1-3):25-33.

64. Yung AR, Phillips LJ, Nelson B, et al. Randomized controlled trial of interventions for young people at ultra high risk for psychosis: 6-month analysis. J Clin Psychiatry. 2011;72(4):430-440.

65. McGorry PD, Nelson B, Phillips LJ, et al. Randomized controlled trial of interventions for young people at ultra-high risk of psychosis: twelve-month outcome. J Clin Psychiatry. 2013;74(4):349-356.

66. McGlashan TH, Zipursky RB, Perkins DO. Randomized, double-blind trial of olanzapine versus placebo in patients prodromally symptomatic for psychosis. Am J Psychiatry. 2006;163(5):790-799.

67. Ruhrmann S, Bechdolf A, Kuhn KU, et al. Acute effects of treatment for prodromal symptoms for people putatively in a late initial prodromal state of psychosis. Br J Psychiatry. 2007;191:88-95.

68. Woods SW, Tully EM, Walsh BC, et al. Aripiprazole in the treatment of the psychosis prodrome: an open-label pilot study. Br J Psychiatry. 2007;191:96-101

69. Rolland B, Geoffroy PA, Jardri R, Cottencin O. Aripiprazole for treating cannabis-induced psychotic symptoms in ultrahigh-risk individuals. Clin Neuropharmacol. 2013;36(3):98-99.

70. Stafford MR, Jackson H, Mayo-Wilson E, Morrison AP, Kendall T. Early interventions to prevent psychosis: systematic review and meta-analysis. BMJ. 2013;346:1-13.

71. Preti A, Cella M. Randomized-controlled trials in people at ultra high risk of psychosis: a review of treatment effectiveness. Schizophr Res. 2010;123(1):30-36.

72. Covell NH, Weissman EM, Schell B, et al. Distress with medication side effects among persons with severe mental illness. Adm Policy Ment Health. 2007;34(5):435-442.

73. Pogge DL, Singer MB, Harvey PD. Rates and predictors of adherence with atypical antipsychotic medication: a follow-up study of adolescent inpatients. J Child Adolesc Psychopharmacol. 2005;15(6):901-912.

74. Maayan L, Correll CU. Weight gain and metabolic risks associated with antipsychotic medications in children and adolescents. J Child Adolesc Psychopharmacol. 2011;21(6):517-535.

75. Roke Y, van Harten PN, Boot AM, Buitelaar JK. Antipsychotic medication in children and adolescents: a descriptive review of the effects on prolactin level and associated side effects. J Child Adolesc Psychopharmacol. 2009;19(4):403-414.

76. Cornblatt BA, Lencz T, Smith CW, et al. Can antidepressants be used to treat the schizophrenia prodrome? Results of a prospective, naturalistic treatment study of adolescents. J Clin Psychiatry. 2007;68(4): 546-557.

77. Fusar-Poli P, Valmaggia L, McGuire P. Can antidepressants prevent psychosis? Lancet. 2007;370(9601):1746-1748.

78. Walker EF, Cornblatt BA, Addington J, et al. The relation of antipsychotic and antidepressant medication with baseline symptoms and symptom progression: a naturalistic study of the North American Prodrome Longitudinal Sample. Schizophr Res. 2009;115(1):50-57.

79. Berger GE, Wood SJ, Ross M, et al. Neuroprotective effects of low-dose lithium in individuals at ultra-high risk for psychosis. A longitudinal MRI/MRS study. Curr Pharm Des. 2012;18(4):570-575.
80. Combs DR, Adams SD, Penn DL, Roberts D, Tiegreen J, Stem P. Social cognition and interaction training (SCIT) for inpatients with schizophrenia spectrum disorders: preliminary findings. Schizophr Res. 2007;91(1-3):112-116.

81. Rathod S, Turkington D. Cognitive-behaviour therapy for schizophrenia: a review. Curr Opin Psychiatry. 2005;18(2):159-163.

82. Morrison AP, French P, Walford L, et al. Cognitive therapy for the prevention of psychosis in people at ultra-high risk. Br J Psychiatry. 2004; 185:291-297.

83. Morrison AP, French P, Parker S, et al. Three-year follow-up of a randomized controlled trial of cognitive therapy for the prevention of psychosis in people at ultrahigh risk. Schizophr Bull. 2007;33(3): 682-687.

84. Bechdolf A, Wagner M, Veith V, et al. Randomized controlled multicentre trial of cognitive behavior therapy in the early initial prodromal state: effects on social adjustment post treatment. Early Intervent Psychiatry. 2007;1(1):71-78.

85. Addington J, Epstein I, Liu L, French P, Boydell KM, Zipursky RB. A randomized controlled trial of cognitive behavioral therapy for individuals at clinical high risk of psychosis. Schizophr Res. 2011;125(1):54-61.

86. van der Gaag M, Nieman DH, Rietdijk J, et al. Cognitive behavioral therapy for subjects at ultrahigh risk for developing psychosis: a randomized controlled clinical trial. Schizophr Bull. 2012;38(6):1180-1188.

87. Dauncey MJ, Bicknell RJ. Nutrition and neurodevelopment: mechanisms of developmental dysfunction and disease in later life. Nutr Res Rev. 1999;12(2):231-253.

88. Amminger GP, Schaefer MR, Papageorgiou K, et al. Omega 3 fatty acids reduce the risk of early transition to psychosis in ultra-high risk individuals: a double-blind randomized, placebo-controlled treatment study. Schizophr Bull. 2007;33:418-419.

89. Amminger GP, McGorry PD. Update on $\omega-3$ polyunsaturated fatty acids in early-stage psychotic disorders. Neuropsychopharmacology. 2012;37(2):309-310.

90. Amminger GP, Schaefer MR, Papageorgiou K, et al. Long-chain omega-3 fatty acids for indicated prevention of psychiatric disorders. Arch Gen Psychiatry. 2010;67(2):146-154.

91. Mossaheb N, Schäfer MR, Schlögelhofer M, et al. Effect of omega-3 fatty acids for indicated prevention of young patients at risk for psychosis: when do they begin to be effective? Schizophr Res. 2013;148(1-3):163-167.

92. Amminger GP, Chanen AM, Ohmann S, et al. Omega-3 fatty acid supplementation in adolescents with borderline personality disorder and ultra-high risk criteria for psychosis: a post hoc subgroup analysis of a double-blind, randomized controlled trial. Can J Psychiatry. 2013;58(7): 402-408.

93. Smesny S, Milleit B, Hipler UC, et al. Omega-3 fatty acid supplementation changes intracellular phospholipase A2 activity and membrane fatty acid profiles in individuals at ultra-high risk for psychosis. Mol Psychiatry. Epub March 12, 2013.

94. Lavoie S, Schäfer MR, Whitford TJ, et al. Frontal delta power associated with negative symptoms in ultra-high risk individuals who transitioned to psychosis. Schizophr Res. 2012;138(2-3):206-211.

95. van der Gaag M, Smit F, Bechdolf A, et al. Preventing a first episode of psychosis: meta-analysis of randomized controlled prevention trials of 12 month and longer-term follow-ups. Schizophr Res. 2013;149(1-3): $56-62$.

96. Woods SW, Walsh BC, Hawkins KA, et al. Glycine treatment of the risk syndrome for psychosis: report of two pilot studies. Eur Neuropsychopharmacol. 2012;23(8):931-940.

97. Vázquez-Roque RA, Ramos B, Tecuatl C, et al. Chronic administration of the neurotrophic agent cerebrolysin ameliorates the behavioral and morphological changes induced by neonatal ventral hippocampus lesion in a rat model of schizophrenia. J Neurosci Res. 2012;90(1): 288-306. 
98. Pillai A, Dhandapani KM, Pillai BA, Terry AV Jr, Mahadik SP. Erythropoietin prevents haloperidol treatment-induced neuronal apoptosis through regulation of BDNF. Neuropsychopharmacology. 2008;33(8):1942-1951.

99. Goetghebeur PJ, Lerdrup L, Sylvest A, Dias R. Erythropoietin reverses the attentional set-shifting impairment in a rodent schizophrenia diseaselike model. Psychopharmacology (Berl). 2010;212(4):635-642.
100. Shapiro DI, Cubells JF, Ousley OY, Rockers K, Walker EF. Prodromal symptoms in adolescents with 22q11.2 deletion syndrome and schizotypal personality disorder. Schizophr Res. 2011;129(1): 20-28.

101. Andreasen NC, Carpenter WT Jr, Kane JM, Lasser RA, Marder SR, Weinberger DR. Remission in schizophrenia: proposed criteria and rationale for consensus. Am J Psychiatry. 2005;162(3):441-449.

\section{Publish your work in this journal}

Therapeutics and Clinical Risk Management is an international, peerreviewed journal of clinical therapeutics and risk management, focusing on concise rapid reporting of clinical studies in all therapeutic areas, outcomes, safety, and programs for the effective, safe, and sustained use of medicines. This journal is indexed on PubMed Central, CAS,
EMBase, Scopus and the Elsevier Bibliographic databases. The manuscript management system is completely online and includes a very quick and fair peer-review system, which is all easy to use. Visit http://www.dovepress.com/testimonials.php to read real quotes from published authors.

Submit your manuscript here: http://www.dovepress.com/therapeutics-and-clinical-risk-management-journal 